\title{
INDEX TO VOLUME 64
}

\section{RESEARCH ANNOUNCEMENTS}

Adams, J. F. On the nonexistence of elements of Hopf invariant one, 279.

Albert, A. A. and Thompson, John. Two element generation of the projective unimodular group, 92.

Balakrishnan, A. V. Representation of abstract Riesz potentials of the elliptic type, 288. - Abstract Cauchy problems of the elliptic type, 290.

Bing, R. H. The cartesian product of a certain nonmanifold and a line is $E^{4}, 82$.

Bott, R. and Milnor, John. On the parallelizability of the spheres, 87.

Fleming, W. H. Functions whose partial derivatives are measures, 364.

Goffman, Casper. A class of lattice ordered algebras, 170.

Gomory, R. E. Outline of an algorithm for integer solutions to linear programs, 275.

Griffiths, H. B. Locally trivial homology theories and the Poincare duality theorem, 367.

Halmos, P. R. and Kakutani, Shizuo. Products of symmetries, 77.

Kac, M. and Kesten, Harry. On rapidly mixing transformations and an application to continued fractions, 283.

Kakutani, Shizuo. See Halmos, P. R.

Kendall, D. G. Integral representations for Markov transition probabilities, 358.

Kesten, Harry. See Kac, M.

Kreyszig, Erwin and Todd, John. The radius of univalence of the error function, 363.

Milnor, John. On the Whitehead homomorphism J, 79.

- See Bott, R.

Myhill, J. Recursive equivalence types and combinatorial functions, 373.

Rothaus, O. S. Domains of positivity, 85.

Rudin, M. E. An unshellable triangulation of a tetrahedron, 90.

Rudin, Walter. On isomorphisms of group algebras, 167.

Schechter, Martin. Solution of the Dirichlet problem for equations not necessarily strongly elliptic, 371.

Schoenberg, I. J. Spline functions, convex curves and mechanical quadrature, 352.

Shapiro, Arnold and Whitehead, J. H. C. A proof and extension of Dehn's lemma, 174.

Thompson, John. See Albert, A. A.

Todd, John. See Kreyszig, Erwin.

Whitehead, J. H. C. On 2-spheres in 3-manifolds, 161.

$\longrightarrow$, See Shapiro, Arnold.

\section{RESEARCH PROBLEMS}

Bellman, R. E., 59, 60, 60, 60, 60, 61, 178, 178, 178, 178, 179, 179.

Slepian, Paul, 59.

Taussky, Olga, 124, 124, 124.

Weinberg, Louis, 59.

\section{REPORTS OF MEETINGS AND MISCELLANEOUS ARTICLES}

Birkhoff, Garrett. Von Neumann and lattice theory, no. 3, Part 2, p. 50.

By-Laws of the American Mathematical Society, 402.

Council and Board of Trustees-1957, 43.

Doctorates conferred in 1957, 125.

Endowment Funds, 398. 
Green, J. W. Reports of Meetings of the American Mathematical Society: The April Meeting in New York, 183; The Summer Meeting in Cambridge, 377.

Halmos, P. R. Von Neumann on measure and ergodic theory, no. 3, Part 2, p. 86.

Kadison, R. V. Theory of operators. Part II. Operator algebras, no, 3, Part 2, p. 61.

Klee, V. L., Jr. Reports of Meetings of the American Mathematical Society: The November meeting in Los Angeles, 56; The April meeting in Stanford, 181.

Kuhn, H. W. and Tucker, A. W. John von Neumann's work in the theory of games and mathematical economics, no. 3, Part 2, p. 100.

Meder, A. E., Jr. Report of the treasurer, 62.

Murray, F. J. The theory of operators. Part I. Single operators, Part 2, no. 3, p. 57. von Neumann, John. See Birkhoff, Garrett, Halmos, P. R., Kadison, R. V., Kuhn, H. W., Murray, F. J., Shannon, C. E., Ulam, S., Van Hove, Léon.

Pierce, R. S. Reports of Meetings of the American Mathematical Society: The June Meeting in Corvallis, 292.

Representatives and Committees of the Society, 395.

Roberts, J. H. Reports of the Meetings of the American Mathematical Society: The November meeting in Coral Gables, 57.

Schafer, R. D. Reports of Meetings of the American Mathematical Society: The October meeting in Washington, 31; The February Meeting in New York, 104; The April meeting in New York, 183; The Summer Meeting in Cambridge, 377.

Shannon, C. E. Von Nuemann's contributions to automata theory, no. 3, Part 2, p. 123. Tucker, A. W. See Kuhn, H. W.

Ulam, S. John von Neumann, 1903-1957, no. 3, Part 2, p. 1.

Van Hove, Léon. Von Neumann's contribution to quantum theory, no. 3, Part 2, p. 95.

Youngs, J. W. T. Reports of Meetings of the American Mathematical Society: The November meeting in Columbia, 58; The Annual meeting in Cincinnati, 94; The April Meeting in Chicago, 180.

\section{BOOK REVIEWS}

Aleksandrov, P. S. Combinatorial topology. Vol. II. The Betti groups. Trans. by Horace Komm. Ky Fan, 300.

Algebraic geometry and topology. A symposium in honor of S. Lefschetz. Ed. by R. H.

Fox, D. C. Spencer and A. W. Tucker.

Armstrong, A. H. See Mikhlin, S. G.

Artin, E. Geometric algebra. A. T. Schafer, 35.

Aumann, J. R. See Hausdorff, F.

Bagemihl, F. See Bourbaki, N.

Bieberbach, Ludwig. Einfuhrung in die Theorie der Differentialgleichungen im reellen Gebiet. E. A. Coddington, 71.

Boron, L. F. See Kolmogorov, A. N.

Bourbaki, N. Intégration. Chapter V. M. E. Munroe, 105.

$\longrightarrow$, Therorie des ensembles (Chapter III). F. Bagemihl, 390.

Brown, Arlen. See Kolmogorov, A. N.

Busemann, Herbert. See Eggleston, H. G.

Cassels, J. W. S. An introduction to Diophantine approximation. W. J. LeVeque, 65.

Chern, S. S. See Hirzebruch, F.

Chung, K. L. See van der Waerden, B. L.

Coddington, E. A. See Bieberbach, Ludwig.

Coxeter, H. S. M. and Moser, W. O. J. Generators and relations for discrete groups. Marshall Hall, Jr., 106.

Crampe, Sibylla. See Maeda, Fumitomo. 
Darling, D. A. See Grenander, Ulf.

Davis, P. J. See Kunz, K. S.

Diliberto, S. P. See Siegel, C. L.

Donoghue, W. F., Jr. See Gould, S. H.

Eggleston, H. G. Convexity. Herbert Busemann, 295. 298.

Eilenberg, S. and Steenrod, N. Foundations of algebraic topology. E. H. Spanier, 190. Fan, Ky. See Aleksandrov, P. S.

Federer, Herbert. See Whitney, Hassler.

Feller, W. An introduction to probability theory and its applications. Vol. 1, 395.

Fine, N. J. See Jeffery, R. L.

Flügge, S. See Handbuch der Physik.

Fomin, S. V. See Kolmogorov, A. N.

Fox, L. The numerical solution of two-point boundary value problems in ordinary differential equations. Wolfgang Wasow, 296.

Fox, R. H. See Algebraic geometry and topology.

- See Wallace, A. H.

Franklin, Philip. See Handbuch der Physik.

Gale, David. See Luce, R. D.

Geiringer, Hilda. See von Mises, R.

Goodstein, R. L. Mathematical logic. Hartley Rogers, Jr., 32.

Gould, S. H. Variational methods for eigenvalue problems. W. F. Donoghue, Jr., 111.

Grenander, Ulf and Rosenblatt, Murray. Statistical analysis of stationary time series. D. A. Darling, 70.

Haas, Felix. See Lefschetz, S.

Hall, Marshall, Jr. See Coxeter, H. S. M.

Halperin, Israel. See Maeda, Fumitomo.

Handbuch der Physik. Band I, Mathematische Methoden I. Ed. by S. Flügge. Philip Franklin, 41.

Hartman, S. and Mikusinski, J. Teoria miary i calki Lebesgue'a. Stanislaw Leja, 385.

Hausdorff, F. Set theory. Trans. by John R. Aumann et al, 394.

Heins, A. E. See Tricomi, F. G. , See Mihlin, S. G.

Hirzebruch, F. Neue topologische Methoden in der algebraischen Geometrie. S. S. Chern, 119.

Iwasawa, Kenkichi. See Meyer, Curt.

Jeffery, R. L. Trigonometric series. A survey. N. J. Fine, 73.

Jenkins, J. A. See Springer, George.

Kolmogorov, A. N. and Fomin, S. V. Elements of the theory of functions and functional analysis. Vol. I. Metric and normed spaces. Trans. from the Russian by L. Boron. Arlen Brown, 198.

Komm, Horace. See Aleksandrov, P. S.

Kunz, K. S. Numerical analysis. P. J. Davis, 112.

Kuratowski, C. Topologie. Vol. 1, 393.

Lanczos, Cornelius. Applied analysis, John Todd, 210.

Lefschetz, S. See Algebraic geometry and topology.

- Differential equations: Geometric theory. Felix Haas, 203.

Leja, Stanislaw. See Hartman, S.

LeVeque, W. J. See Cassels, J. W. S.

$\longrightarrow$, See Schneider, Th.

Linear algebras. See National Academy of Sciences. 
Luce, R. D. and Raiffa, Howard. Games and decision: Introduction and critical survey. David Gale, 108.

Maeda, Fumitomo. Kontinuerliche Geometrien. Trans. from the Japanese by Sibylla Crampe, Gunter Pickert and Rudolf Schauffler. Israel Halperin, 386.

Meyer, Curt. Die Berechnung der Klassenzahl Abelscher Körper über quadratischen Zahlkörpern. Kenkichi Iwasawa, 211.

Mikhlin, S. G. Integral equations and their applications to certain problems in mechanics, mathematical physics and technology. Trans. from the Russian by A. H. Armstrong. A. E. Heins, 198.

Mikusinski, J. See Hartman, S.

Milnor, John. See Steenrod, N.

von Mises, R. Probability, statistics and truth. $2 \mathrm{~d}$ rev. English ed. prepared by Hilda Geiringer, 394.

Moser, W. O. J. See Coxeter, H. S. M.

Munroe, M. E. See Bourbaki, N.

National Academy of Sciences, National Research Council. Linear algebras. Publication 502, 393.

Nering, E. D. See Thrall, R. M.

Niven, Ivan. Irrational numbers. R. A. Rosenbaum, 68.

Perron, Oskar. Die Lehre von den Kettenbruchen. Vol. II. Analystisch-funktionentheoretische Kettenbruche. W. T. Scott, 299.

Pickert, Gunter. See Maeda, Fumitomo.

Pontrajagin, L. Topological groups, 394.

Prachar, Karl. Primzahlverteilung. A. L. Whiteman, 113.

Raiffa, H. See Luce, R. D.

Rogers, Hartley, Jr. See Goodstein, R. L.

Rosenbaum, R. A. See Niven, Ivan.

Rosenblatt, Murray. See Grenander, Ulf.

Schafer, A. T. See Artin, E.

Schauffler, Rudolf. See Maeda, Fumitomo.

Schneider, Th. Einfilhrung in die transzendenten Zahlen. W. J. LeVeque, 206.

Scott, W. T. See Perron, Oskar.

Siegel, C. L. Vorlesungen ïber Himmelsmechanik. S. P. Diliberto, 192.

Sierpinski, W. Hypothèse du continu, 394.

Spanier, E. H. See Eilenberg, S.

Spencer, D. C. See Algebraic geometry and topology.

Springer, George. Introduction to Riemann surfaces. J. A. Jenkins, 382.

Steenrod, N. See Eilenberg, S.

, The topology of fibre bundles. John Milnor, 202.

Thrall, R. M. and Tornheim, Leonard. Vector spaces and matrices. E. D. Nering, 73.

Todd, John. See Lanczos, Cornelius.

Tornheim, Leonard. See Thrall, R. M.

Tricomi, F. G. Integral equations. A. E. Heins, 197.

Tucker, A. W. See Algebraic geometry and topology.

van der Waerden, B. L. Mathematische Statistik. K. L. Chung, 293.

Wallace, A. H. An introduction to algebraic topology. R. H. Fox, 391.

Wasow, Wolfgang. See Fox, L.

Whiteman, A. L. See Prachar, Karl.

Whitney, Hassler. Geometric integration theory. Herbert Federer, 38. 


\section{INVITED ADDRESSES}

Clifford, A. H., 57.

Totally ordered commutative semigroups, 305.

Dunford, Nelson, 94.

- A survey of the theory of spectral operators, 217.

Dyer, Eldon, 377.

Gottschalk, W. H., 31.

, Minimal sets: an introduction to topological dynamics, 336.

Levine, Harold, 56.

Moore, J. C., 183.

Moser, Jürgen, 377.

Muller, H. J., 94.

-, Evolution by mutation, 137.

Nikodym, O. M., 377.

Nirenberg, Louis, 104.

Papakyriakopoulos, C. D., 94.

, Some problems on 3-dimensional manifolds, 317.

Pettis, B. J., 377.

Piranian, George. The boundary of a simply connected domain, 45 .

Pitcher, Everett. Inequalities of critical point theory, 1.

Rogosinski, W. W., 181.

Rohrbach, Hans, 57.

Rudin, Walter, 377.

Sario, Leo, 292.

Singer, I. M., 183.

Whaples, George, 180.

Zelinsky, Daniel, 58. 